IZA DP No. 6815

Incentives and Group Identity

Paolo Masella

Stephan Meier

Philipp Zahn

August 2012

Forschungsinstitut

zur Zukunft der Arbeit

Institute for the Study

of Labor 


\title{
Incentives and Group Identity
}

\author{
Paolo Masella \\ University of Mannheim
}

Stephan Meier

Columbia University

and IZA

Philipp Zahn

University of Mannheim

\section{Discussion Paper No. 6815 \\ August 2012}

\author{
IZA \\ P.O. Box 7240 \\ 53072 Bonn \\ Germany \\ Phone: +49-228-3894-0 \\ Fax: +49-228-3894-180 \\ E-mail: iza@iza.org
}

\begin{abstract}
Any opinions expressed here are those of the author(s) and not those of IZA. Research published in this series may include views on policy, but the institute itself takes no institutional policy positions.

The Institute for the Study of Labor (IZA) in Bonn is a local and virtual international research center and a place of communication between science, politics and business. IZA is an independent nonprofit organization supported by Deutsche Post Foundation. The center is associated with the University of Bonn and offers a stimulating research environment through its international network, workshops and conferences, data service, project support, research visits and doctoral program. IZA engages in (i) original and internationally competitive research in all fields of labor economics, (ii) development of policy concepts, and (iii) dissemination of research results and concepts to the interested public.
\end{abstract}

IZA Discussion Papers often represent preliminary work and are circulated to encourage discussion. Citation of such a paper should account for its provisional character. A revised version may be available directly from the author. 
IZA Discussion Paper No. 6815

August 2012

\section{ABSTRACT}

\section{Incentives and Group Identity*}

This paper investigates in a principal-agent environment whether and how group membership influences the effectiveness of incentives and when incentives can have "hidden costs", i.e., a detrimental effect. We show experimentally that in all interactions control mechanisms can have hidden costs for reasons specific to group membership. In within-group interactions control has detrimental effects because the agent does not expect to be controlled and reacts negatively when being controlled. In between-group interactions, agents perceive control more hostile once we condition on their beliefs about principal's behavior. Our finding contributes to the micro-foundation of psychological effects of incentives.

JEL Classification: C91, D03, Z13

Keywords: $\quad$ social identity, social preferences, incentives, motivation, crowding out, trust, experiment

Corresponding author:

Stephan Meier

Columbia University GSB

3022 Broadway

New York, NY 10027

USA

E-mail: sm3087@columbia.edu

\footnotetext{
* We thank Steffen Altman, Yan Chen, Dirk Engelmann, Jana Friedrichsen, Hans-Peter Grüner, Astrid Hopfensitz, Sherry Li, Marie-Claire Villeval and seminar participants at Mannheim University, Toulouse School of Economics, and the ESA 2012 Conference in New York for helpful comments. We are grateful to Yan Chen, Sherry Li, Matteo Ploner, James Tremewan, and Anthony Ziegelmeyer who provided us with software source code and original instructions. Financial support by the University of Mannheim is gratefully acknowledged.
} 


\section{Introduction}

An important premise in agency theory is the power of incentives: without proper incentives, agents would not put in enough effort and would shirk substantially. As a consequence, principals need to use incentives and control systems in order to make agents perform. While incentives do increase effort in certain settings (e.g., Lazear, 2000), they can also have detrimental effects, i.e., individuals put in less effort in the presence of monetary incentives than without (for reviews of the literature, see Frey and Jegen, 2001; Fehr and Falk, 2002; Gneezy et al., 2011). Control as one particular form of incentive can be particularly problematic as results by Falk and Kosfeld (2006) indicate. The implementation of a control mechanism that forces agents to put in at least some effort can have substantial "hidden costs" leading to lower effort than if agents are not controlled by the principal. ${ }^{1}$ While there is growing evidence that incentives can be detrimental in principal-agent situations, the conditions when incentives turn detrimental are less understood.

This paper investigates whether "hidden costs of incentives and control" are particularly relevant when the principal and the agents have a close relationship (as argued in Frey, 1993; Dickinson and Villeval, 2008). Detrimental effects of incentives and control mechanisms might be restricted to interactions among friends, family members or in-group members as they are more likely to be perceived by the agent as distrust and a violation of a psychological contract (e.g. Fehr and Falk, 2002; Sliwka, 2007; Ellingsen and Johannesson, 2008; Von Siemens, 2011). Many examples of hidden cost of incentives refer, in fact, to interactions within-groups, e.g. negative effect of incentivizing one's child to help in the house (Frey and Jegen, 2001), helping a friend move for free or for pay (Heyman

\footnotetext{
${ }^{1}$ Similar detrimental effects of control and incentives are observed in a number of other experimental studies (e.g. Fehr and Rockenbach, 2003; Fehr and List, 2004; Fehr et al., 2007; Gächter et al., 2010). And hidden benefits of delegation (i.e., the flipside of control) are also observed (Charness et al., 2011).
} 
and Ariely, 2004). However, in many situations incentives are used not within-groups but in between-groups interactions. For example, many principal-agent relationships are between firms, i.e., buyers and suppliers. Even within firms, the principal often belongs to and identifies with a different and very salient team or group: the management (white collar) controls the workers (blue collars) or provides incentives to the salesforce. It is well known that in such between-group interactions, trust is lower to begin with (e.g. Fershtman and Gneezy, 2001; Chen and Li, 2009; Falk and Zehnder, 2007) and incentives might be less detrimental as agents do notexpect their out-group principals to be trusting. If the incentive effect is less detrimental in between-group interactions, then the effect might be less relevant in a situation in which agents do notidentify with the same group as the principals.

We test the impact of group identity on the effectiveness of incentives in an experiment à la Falk and Kosfeld (2006) in which all participants belong to one of two different groups (the group manipulation is implemented similar to Chen and Li, 2009). Principals have to decide whether or not they want to control their agent by setting a minimum transfer level. Agents then decide on tranfers. Our experiment is able to replicate both that a) control can be detrimental and reduce transfers and that b) group membership leads to substantial in-group bias, i.e., agents provide higher transfers for in-group principals. More importantly, our setting allows analyzing whether the "hidden cost of control" are group-specific, i.e., whether control is perceived differently in within-group and betweengroup matchings.

The results show that hidden costs of control are as strong in between-group matchings as in within-group matchings. But while the overall effectiveness of incentives seems not to depend on the social distance between principal and agents through joint group identity, the mechanisms for how incentives are perceived are group-specific. In withingroup interactions "hidden costs of control" occur because agents expect the principal 
not to control. When principals control nevertheless, agents reduce their transfers significantly as a reaction. If the agent and the principal do notshare the same group, however, the mechanism is different: Keeping agents' beliefs about the principal's behavior constant, agents perceive control more hostile in a between-group matching. This "hostility effect" is consistent with previous findings (Chen and Li 2009 and Götte et al. 2012a), who show that when minimal groups are artificially generated, punishment for misbehavior is stronger in between-group than in within-group interactions. ${ }^{2}$

Our results make two important contributions to the literature: First, our paper contributes to the discussion of the impact of group identity in organizations. Akerlof and Kranton (2005) stressed the importance of group identity for organizational design and incentive schemes - introducing a long research tradition in social psychology to economics. ${ }^{3}$ While there is a growing literature in economics on the effects of group identity on individual behavior (e.g. Fershtman and Gneezy, 2001; Götte et al., 2006; Bernhard et al., 2006; Charness et al., 2007; Chen and Li, 2009; Sutter, 2009; Chen and Chen, 2011; Götte et al., 2012b,a), there are few papers that investigate how social interactions (within or across firms) affect the efficacy of incentives and control schemes. Bandiera et al. $(2009,2010)$ show how social connections among agents affect the effectiveness of different incentive schemes. Our paper focuses on the effectiveness of principal's control without lifting anonymity as in Dickinson and Villeval (2008), who study the impact of monitoring. ${ }^{4}$ Our results show that incentive schemes can have detrimental effects not only in principal-agents relationship with close social ties. Incentives and control schemes

\footnotetext{
${ }^{2}$ When real groups are considered, however, as in Götte et al. (2006) and Bernhard et al. (2006), individuals punish violators of social norms harsher in between-group interactions only if the victim of the violation belongs to their own group.

${ }^{3}$ In the management literature, identification with a firm is also been argued to be an important aspect of firm's performance through improving coordination and cooperation (e.g Kogut and Zander, 1996).

${ }^{4}$ They generate interpersonal relationships between principal and agents by removing subject anonymity, introducing subjects to one-another and allowing them to engage in five-minutes of faceto-face interactions. They find that monitoring incentives are no more efficient when anonymity is lifted and social exchange between principal and agent is allowed.
} 
are perceived very differently in between vs. within-group matchings indicating that group membership in principal-agent relationships is important.

Secondly, we contribute to the literature in economics on psychological effects of incentives. While a number of previous papers show that incentives can have "hidden costs" (for a review, see Gneezy et al., 2011), relatively little is known about the conditions under which incentives or control mechanisms are more likely to have detrimental effects. Our paper shows that 'situational' factors critically affect how incentives are perceived, and as a result, when they are more likely to work as predicted by traditional agency theory and when not. In the end, in both between- and in within-group matchings the implementation of a control mechanism has "hidden costs", but for different reasons. These different, group-specific reasons contribute to a micro-foundation of psychological effects of incentives.

The paper proceeds as follows: in section 2 we present the experimental design. Section 3 discusses our behavioral hypotheses based on a simple model that illustrates the different effects group identity can have on incentives. Section 4 presents the results and section 5 concludes.

\section{Experimental Design}

To analyze how group identity affects the "hidden cost of incentives", participants are, first, assigned to different groups and, second, interact in a stylized principal-agent relationship in which the principal can incentivize the agent by imposing a control mechanism. The choice of the principal-agent interaction and the group treatment were guided by the desire to create a setup in which incentives can be detrimental and in which group identity is quickly established while still being created randomly. 


\subsection{Group Manipulation}

We randomly manipulate group identity in the lab using three steps similar to Chen and Li (2009): ${ }^{5}$ First, each individual was presented a pair of five pictures by two artists (Klee and Kandinsky). For each pair, subjects had to choose one painting. Subjects were then ranked according to their choices and assigned to either the "Kandinsky" or the "Klee" group. To guarantee equally large groups, there was a random draw that assigned subjects such that groups were balanced in the case of an initally unbalanced assignment. ${ }^{6}$ A subject knew that her own and the choices of the other subjects would be used to assign two equally large groups. Subjects were not informed about the details. After each subject had made a decision, participants learned to which group they had been assigned.

Secondly, each subject participated in a quiz. ${ }^{7}$ Within their own group, subjects could communicate via a chat program to discuss the questions. While subjects could discuss with group members which answers were correct, each subject had to answer individually and in private, i.e., decisions were not observed by other subjects.

Thirdly, to further strengthen group identity we introduced an incentivized group competition using the outcome in the quiz as scores: the group with the highest average of correct answers received a prize of 8 EUR per group member. Results by Eckel and Grossman (2005), Charness et al. (2007), and Götte et al. (2012b) indicate that competition among groups induced by financial rewards have a strong effect on group identity.

\footnotetext{
${ }^{5}$ We thank Yan Chen and Sherry Li for providing us with the original z-tree code and the original instructions of Chen and Li (2009). Moreover, we thank James Tremewan for providing us with the z-tree code for the chat treatment that was used in Tremewan (2010).

${ }^{6}$ Subjects from the initially larger group were reassigned to the smaller group by using the ranking of choices. Among those subjects who had the same ranking and were closest in their choices to the smaller group, a random variable was drawn which then determined which subject was reassigned.

${ }^{7}$ The quiz comprised five questions covering two more painting pairs and three political-economic issues regarding Germany (the rate of inflation, the budget of the Department of Defense, and the number of secretaries in the federal government).
} 
The prize was announced before the quiz started. The outcome of the group competition, however, was only revealed at the end of the experiment when subjects had already made all their decisions.

The groups are almost 'minimal groups' according to the standards in psychology (e.g. Tajfel and Turner, 1979) and are not real groups as in, e.g., Fershtman and Gneezy (2001); Bernhard et al. (2006). The advantage of using this approach is that the groups are neither endogenously formed nor do they differ in any observable characteristics like ethnicity which would make inference about the effect of group identity per se very difficult. ${ }^{8}$ Another approach would have been to use randomly assigned real groups (e.g., Götte et al., 2006). Our approach allows us to see whether a minimal identity already has an effect. $^{9}$

\subsection{Principal-Agent Interaction}

After we manipulated group identity, subjects played a principal-agent game based on the design by Falk and Kosfeld (2006). ${ }^{10}$ The agent decides on whether to make a transfer. The transfer is tripled by the experimenter and represents the payoff of the principal. Before the agent decides, the principal can restrict the agent's choice set to an exogenously given lower bound (the minimum transfer the agent has to make) or leave the agent's set unrestricted.

\footnotetext{
${ }^{8}$ Methodologically, we vary the social distance between principal and agents without lifting the anonymity as other studies had to do. Previous approaches make it difficult to isolate anonymity effects from effects of the closeness of the principal-agent relationship (e.g., Dufwenberg and Muren, 2006; Bohnet and Frey, 1999; Dickinson and Villeval, 2008).

${ }^{9}$ In half of the sessions we also added a dictator game stage to see whether it can further increase group identity. The dictator game stage took place after the group manipulation and before the simplified gift exchange game stage described in this section. As it does not change the results qualitatively, we analyze all the sessions together in the main text and relegate the results separated for the condition with and without a dictator game to the Appendix (see tables B2 and B3).

${ }^{10}$ We thank Matteo Ploner and Anthony Ziegelmeyer (Ziegelmeyer et al., 2012) for providing us with the original instructions and the original z-tree code of Falk and Kosfeld (2006).
} 
An agent's payoff is $y_{A}=24-t$. He can choose $t$ from $t \in\{0, \ldots, 24\}$ points if he is not controlled by the principal and from $t \in\{1, \ldots, 24\}$ points if he is controlled by the principal. We explicitly choose parameters that are most likely to generate "hidden costs of control" (Falk and Kosfeld, 2006; Gneezy and Rustichini, 2000) as we are interested in studying when these costs are most prevalent.

The principal's payoff is $y_{P}=t \cdot 3$. Hence, the principal can secure himself a payoff of at least 3 points if he controls the agent.

Subjects were randomly assigned to be either an agent or a principal for the whole experiment. Subjects played two rounds of this principal-agent interaction. In the first round, one half of principals and agents was randomly matched with a counterpart from the same group, the other half was randomly matched with a counterpart from the other group. In the second round, each subject was matched in the opposite constellation. When we check whether there are any order effects by controlling for the round, the results do not change. ${ }^{11}$

All interactions were anonymous. Subjects only knew the group membership of the subject they interacted with, i.e., whether the counterpart belonged to the same or to the other group. Subjects also knew that they would be matched with a different participant in the second round. ${ }^{12}$

Subjects learned the outcome of the interaction only after the second round was completed. Subjects were then paid one randomly drawn round.

As in Falk and Kosfeld (2006) we used the strategy method to elicit a response by agents for the two possible cases, being controlled and not being controlled in each round. While it is possible that the strategy method influences results, two points have

\footnotetext{
${ }^{11}$ Results are not reported here. They are available upon request.

${ }^{12}$ Subjects did not know in advance that they would be matched with an in-group member in one round and an out-group member in the other round.
} 
to be noted: First, the empiricial evidence that the strategy method leads to a different behavior than the direct-response method is mixed. In a recent survey, Brandts and Charness (2011) report on 29 studies investigating the differences between the strategy and the direct-response method. Out of these twenty-nine studies, four find differences, nine find mixed evidence, and sixteen find no differences. Secondly and more importantly, Falk and Kosfeld (2006) conduct a control treatment (SR10) where they do not find any significant differences between the two methods. As we are using the same design, we are confident that our results are robust to the direct-response method also. ${ }^{13}$

In addition, we elicited beliefs from agents as well as from principals. After they had made a decision in each round, we asked them what they believed the principal (agent) would do. ${ }^{14}$

\subsection{Procedures}

The experiment was conducted in the experimental lab at Mannheim University in September 2011. The experiment was computerized using z-tree (Fischbacher, 2007). Subjects were students from the University of Mannheim from different fields. They were recruited using the online system ORSEE (Greiner, 2004).

In total 128 subjects participated in 16 sessions. A session lasted between 35 and 45 minutes. One point in the experiment represents 0.5 EUR and average earnings were 16.80 EUR (about $\$ 23$ ).

\footnotetext{
${ }^{13}$ Falk and Kosfeld (2006) is also among the surveyed articles in Brandts and Charness (2011) which do not find differences.

${ }^{14}$ The exact question for the agent was: "What do you think, will participant A constrain you to transfer at least 1 point?". For the principal it was: "What do you think, how many points will participant A transfer if you allow him to decide freely?" and "What do you think, how many points will participant A transfer if you constrain him to transfer at least 1 point?". As in Falk and Kosfeld (2006) belief elicitation was not incentivized. Subjects were informed that their responses had no influence on their payoffs.
} 


\section{Behavioral Predictions}

We are interested in what influences the effect of control and how it depends on group identity of the principal and the agent. We set $\pi(m, \tau)$ for the effect of control, that is, the transfer when an agent is not controlled minus the transfer when an agent is controlled. $\pi(m, \tau)$ depends on two factors: $m$, the matching between an agent and a principal, and $\tau$, the beliefs of an agent about the action a principal will decide to undertake. The matching is $m=w$ if the agent and the principal belong to the same group (within-group matching) and $m=b$ otherwise (between-group matching); $\tau$ can take on only two values, $\tau=n$ if the agent expects to be trusted by the principal and therefore not to be controlled by him, and $\tau=c$, if he expects to be controlled.

Group identity of the principal and the agent can influence the effectiveness of incentives in several ways. Below we outline three channels through which group identity can impact how agents react to control. While the first channel is concerned with the level of prosocial behavior in the absence of control, the other two deal with how control is perceived by an agent.

1. "Prosocial effect": In general, hidden costs of control can only be observed if agents make positive transfers without control (prosocial behavior). As such, control is effective if agents do nottransfer without control, i.e., if their transfer is zero when not being controlled.

It is typically observed that shared group identity substantially increases prosocial behavior within-group (for a review of research on in-group bias, see Hewstone et al. (2002)). As a result, control is going to be more effective in a between-group matching because of two effects. First, more agents will be pushed from a zero transfer to the minimum transfer of 1 in a between-group matching. Secondly, in a 
between-group matching, there are fewer agents behaving prosocially and thus fewer agents whose transfer can be crowded out by the incentive. If $s_{m}(0)$ is the fraction of agents that chooses a transfer of zero in a matching $m$ and $s_{m}(>1)$ the fraction of agents that chooses a transfer larger than 1 in a matching $m$, we then expect both $s_{w}(0)<s_{b}(0)$ and $s_{w}(>1)>s_{b}(>1)$.

While control mechanically has a positive effect for those individuals who are selfish, for individuals behaving prosocial and whose transfers thereby can be crowded out, we discuss two channels through which control can have a negative effect.

2. "Trust effect": Control as an incentive scheme can have 'hidden costs' as it signals distrust of the principal towards the agent (e.g. Fehr and List, 2004; Falk and Kosfeld, 2006). Agents punish principals more harshly if they do not expect to be distrusted by the principal. In the above framework, we therefore expect $\pi(m, n)-\pi(m, c) \equiv \gamma>0$, for all $m$ and conditional on a transfer larger than 1 . Therefore, independent of the matching $m$, the crowding out will be stronger when an agent does not expect to be controlled $(\tau=n)$.

Denote with $b_{m}$ the share of agents who believe to be controlled in a matching $m$ (conditional on transfers larger than 1). We expect that group membership will affect this share of agents, that is, in a between-group matching more agents will expect to be controlled $\left(b_{b}>b_{w}\right)$. As a result, the share of individuals that will be disappointed by a principal's decision to control will be higher in a within-group matching.

3.) "Hostility effect": A violation of expected trust might be just one reason why control can have hidden costs. Given an agent's expectation about principals' actions, an agent might perceive control as more or less 'offensive' as he or she will interpret 
what control signals about a principal's view on the agent or attribute the action by the principal to his or her attitudes or traits. Group identity can change this perception of actions from in- or out-group members substantially. The famous 'group attribution error' (Allison and Messick, 1985) as one way of group specific 'social inference' (Tajfel, 1982; Hastie, 1983) shows that the same actions are perceived differently if taken by an in- or out-group member. Holding expectations constant, control by an out-group principal is expected to be perceived more negatively than control by an in-group member. That is, we expect $\pi(b, \tau)-\pi(w, \tau) \equiv \delta>0$, for all $\tau$ and transfers larger than 1. So, for given expectations about being controlled or not, control will increase crowding out more strongly in a between-group matching than in a within-group matching.

As a last step we derive the formula for the difference between the average effect of control in a within-group matching and the average effect of control in a between-group matching. To simplify notation, we set $\pi(w, c) \equiv \kappa$. Then, putting the three effects from above together, we get as the difference-in-difference, $\Pi_{w}-\Pi_{b}:{ }^{15}$

$$
\begin{aligned}
\Pi_{w}-\Pi_{b} & =\underbrace{\left(s_{b}(0)-s_{w}(0)\right)+\left[\left(s_{w}(>1)-s_{b}(>1)\right] \kappa\right.}_{\text {Prosocial Effect }} \\
& +\underbrace{\left[s_{w}(>1)\left(1-b_{w}\right)-s_{b}(>1)\left(1-b_{b}\right)\right] \gamma}_{\text {Trust Effect }} \\
& -\underbrace{s_{b}(>1) \delta}_{\text {Hostility Effect }}
\end{aligned}
$$

The three different effects of group membership on the effect of incentives are countervailing. While the 'prosocial effect' and the 'trust effect' predict more hidden costs

\footnotetext{
${ }^{15}$ For the details of the derivation see section Appendix B.1
} 
of control in within-group interactions, the 'hostility effect' predicts more hidden costs in between-group matchings. The net effect in within-group compared to between-group interactions is therefore unclear. We will show in the next section the net effect first and then disentangle the different channels by using information collected during the experimental stage on both the transfers provided by the agents and whether they expect to be controlled by the principal.

\section{Results}

We present the results in two steps: first and most importantly, we discuss the behavior of agents. This part presents the net effect of control on agents in within- and betweengroup interactions and then shows whether some of the channels of crowding out are matching-specific. Secondly, we discuss principals' decision to control.

\subsection{Agents' Behavior}

Our first result replicates the findings in Falk and Kosfeld (2006):

Result 1: We observe "hidden costs of control": Control reduces average transfers by agents.

Figure 1 depicts agents' average transfers depending on matching (between-group or within-group) and choice of the principal (to control or not to control). Across the two treatments transfers are 4.8 points when agents are not being controlled and decline to 3.7 points when agents are being controlled. The average transfer in a between-group (withingroup) matching when not being controlled is 3.4 (6.1) points. When being controlled, the transfer decreases to 2.5 points, or $73 \%$ of the transfer under no control, in a betweengroup matching (4.9 points, respectively $80 \%$, in a within-group matching). In Table 1 


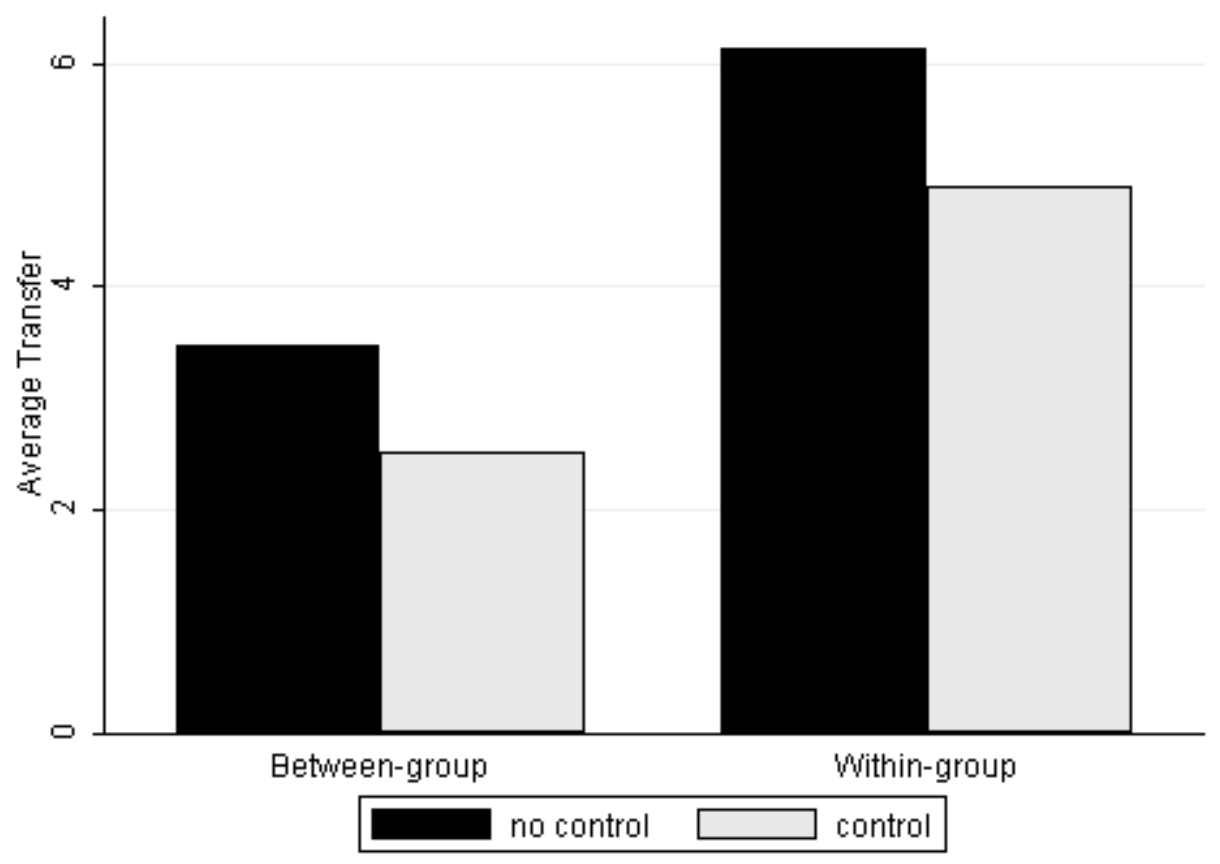

Notes: The figure depicts average individual transfers by agents as a function of control and matching.

Figure 1: Agents' Average Transfer 
Table 1: Agents' Transfers Conditional on Control and Group Matching

\begin{tabular}{lcc}
\hline \hline Dependent Variable: Transfers & $(1)$ & $(2)$ \\
\hline Control $(=1)$ & $-1.094^{* * *}$ & $-0.953^{* * *}$ \\
& $(0.242)$ & $(0.291)$ \\
Within-group matching $(=1)$ & $2.531^{* * *}$ & $2.672^{* * *}$ \\
& $(0.663)$ & $(0.699)$ \\
Control x Within-group & & -0.281 \\
& & $(0.314)$ \\
Constant & & \\
& $3.539^{* * *}$ & $3.469^{* * *}$ \\
$N$ & $(0.444)$ & $(0.474)$ \\
\hline \hline
\end{tabular}

Notes: Standard errors are in parentheses. All columns report results of OLS regressions. Dependent variable is the individual transfer. Standard errors are clustered at the individual level.

Level of significance: ${ }^{*} \mathrm{p}<0.10,{ }^{* *} \mathrm{p}<0.05,{ }^{* * *} \mathrm{p}<0.01$

we report results from an OLS regression of agents' transfer choices in control and group matching. Column (1) shows that control has a significantly negative effect on agents' transfer choices. When comparing our results to Falk and Kosfeld (2006), two points are evident. First, the average transfer by agents who are not controlled is 5.02 points and therefore in the range between our within-group and between-group results. ${ }^{16}$ Secondly, however, the average crowding out is stronger than in our case (average transfer when being controlled is 2.44 points, respectively $48 \%) .{ }^{17}$

Result 2: Group identity affects agents' transfers. Independent of control decisions, agents transfer more in a within-group matching than in a between-group matching.

In line with previous research we observe a clear effect of group identity. Agents

\footnotetext{
${ }^{16}$ Taken from Table 1 (p. 1619) treatment C5. We transformed the numbers into our 24-point-scale to make them comparable. Also note that in Falk and Kosfeld (2006) every transfer by the agent is doubled and not tripled as in our design.

${ }^{17}$ Note that other experiments also report a smaller crowding out effect of control (Ziegelmeyer et al., 2012; Kessler and Leider, 2012).
} 
transfer more points when they are matched with a participant of their own group independently of whether they are controlled or not. In a between-group matching agents transfer $55 \%$ of the average transfer in a within-group matching. Table 1 shows that the effect is statistically highly significant. Our results are similar to Chen and Li (2009, p.442). They find that distributional preferences are affected by group identity. In particular, charity towards in-group members increases by $47 \%$ compared to out-group members.

Result 3: We observe no group identity effect on the average effect of control.

While group identity affects the transfers, it has no impact on how agents react when being controlled. The average difference between the 'effect of control' between withinand between-group matching (i.e., the diff-in-diff) is small (0.28) and not statistically significant as shown in Table 1, column (2).

While the net effect does not differ, in the following, we decompose the diff-in-diff as described in section 3 into three effects: prosocial, trust, and hostility. We first provide evidence for the existence of these three effects and show that they depend on group matching. Then, we identify the parameters described in section 3 and disentangle the effects within the diff-in-diff.

Result 4: Group identity affects the distribution of transfers under no control. More agents transfer zero and fewer agents transfer more than 1 in a between-group matching.

Panel A (Panel B) in Figure 2 shows the distribution of transfers when the agent is not controlled (is controlled) by the principal. Panel A illustrates that group identity affects this distribution. The difference between the two distributions is statistically significant (Mann-Whitney test, $\mathrm{p}<0.01$ ). For the overall effect of control two points are important: First, the share of agents who transfer zero is larger in a between-group matching $\left(s_{b}(0)=\right.$ 
0.28) than in a within-group matching $\left(s_{w}(0)=0.12\right)$ and this difference is statistically significant (Fisher's exact test, $\mathrm{p}<0.05$ ). Therefore, for a larger share of agents control is binding in between-group interactions. Secondly, the share of agents who expend more than 1 under no control - whose transfers thereby can be crowded out - is smaller in a between-group matching $\left(s_{b}(>1)=0.66\right)$ than in a within-group matching $\left(s_{w}(>1)=\right.$ 0.86). This difference is also statistically significant (Fisher's exact test, $\mathrm{p}<0.05$ ).

In the following, we discuss the two other channels outlined in Section 3, trust and hostility. Since they are only relevant to individuals who transfer more than one point when not being controlled, in the empirical analysis further on we only focus on these subjects. In appendix B.4, we provide results including all individuals and not only subjects who exhibit a transfer greater than zero.

Result 5: Agents who expected to be trusted by principals, that is, agents who do not expect to be controlled, reduce transfers more strongly.

The crowding out is mostly driven by agents who initially expected to be trusted by the principal, that is by agents who did not expect to be controlled by them. They show the strongest negative reaction to control: On average, the crowding out, i.e., the reduction of transfers when being controlled, is around 1 point for agents who expect the principal to control. It more than doubles to 2.2 points when they expect not to be controlled. The difference of distributions is statistically significant (Mann-Whitney test, $\mathrm{p}<0.001)$. In our model, this "trust effect" corresponds to $\gamma$.

Result 6: Group identity affects agents' beliefs about the principal's behavior. A larger fraction of agents expects the principal to control in a between-group matching.

Figure 3 displays agents' beliefs about the principal's decision to control by matching when we restrict the sample to agents that transfer more than 1 when not being controlled, that is, we include only agents whose transfers can potentially be crowded out. The 

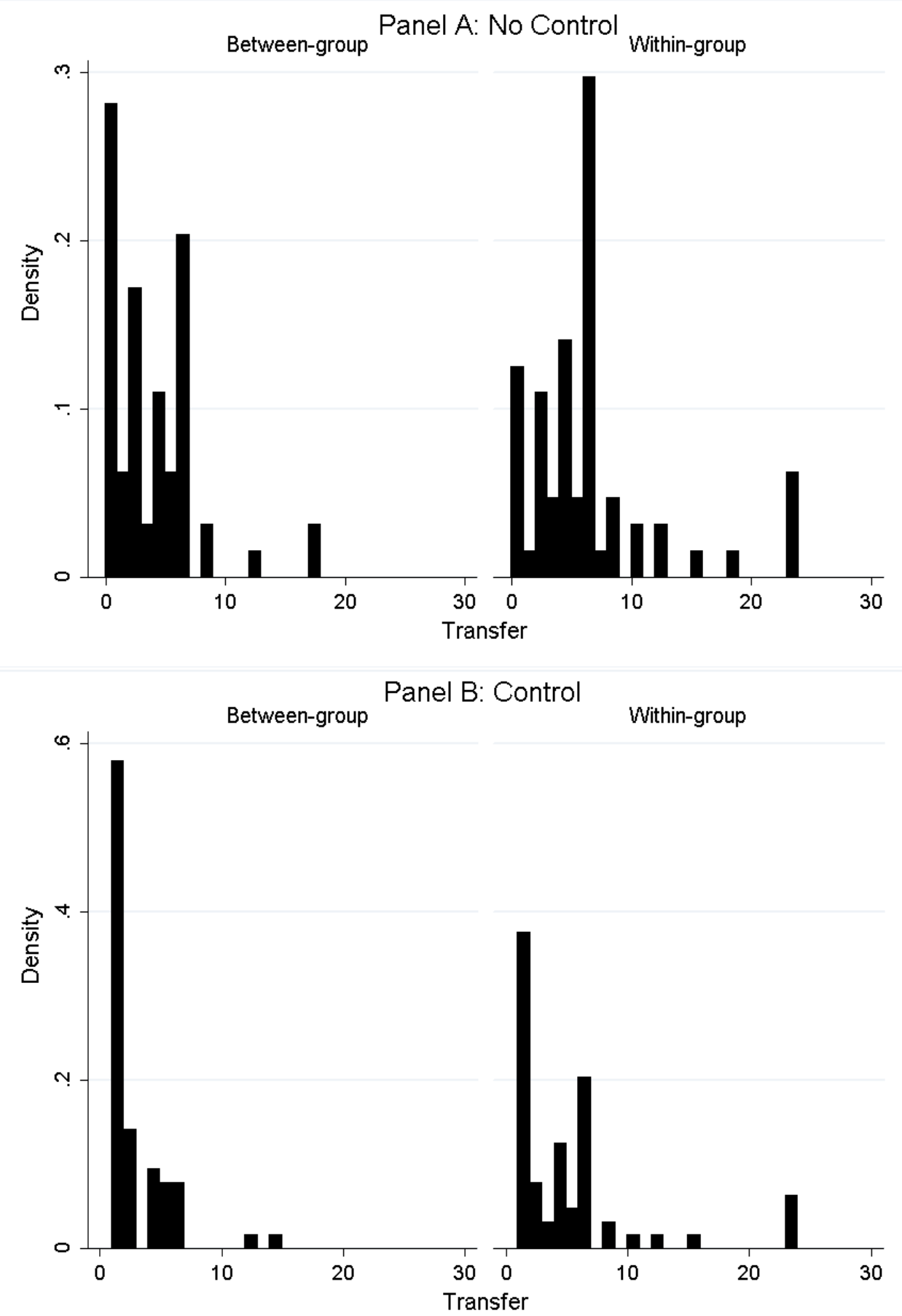

Notes: Panel A shows the distribution of agents' transfers with no control for between- and within-group interactions. Panel B shows the respective distribution when the principal decides to control.

Figure 2: Distribution of Agents' Transfers 


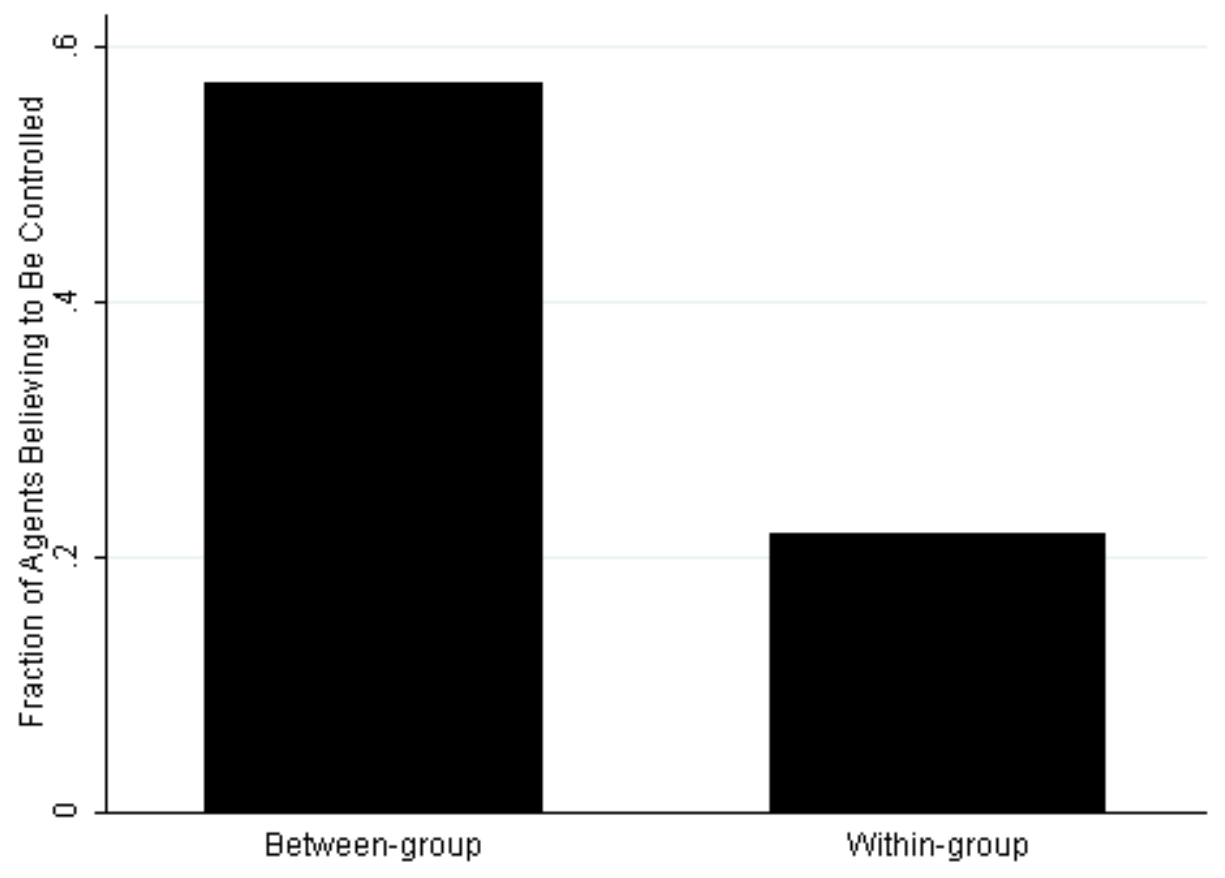

Notes: The figure depicts average individual beliefs about being controlled as a function of matching. We restrict the sample to agents that transfer more than 1 when not being controlled.

Figure 3: Average Beliefs about Principal's Decision to Control

share of agents who expects to be controlled in a between-group matching, $b_{b}=0.57$, is significantly larger than in a within-group matching, $b_{w}=0.21$ (Fisher's exact test, $\mathrm{p}<0.001)$.

Result 5 shows that agents' transfers are crowded out more strongly if they expect principals not to control them. As group identity influences the beliefs of the agents (Result 6), combining these two findings leads crowding out to be stronger in situations in which principals and agents identify with the same group. However, there is a countervailing effect:

Result 7: Agents exhibit a "hostility effect". Keeping beliefs constant, agents reduce transfers more strongly in between-group than in within-group matchings. 
Once we control for their beliefs we find that agents react more negatively to being controlled in a between-group matching. Figure 4 shows the average crowding out, i.e., the transfer when not being controlled minus the transfer when being controlled, for different matchings and different beliefs of agents (being controlled or not being controlled). The figure again focuses on agents who transfer more than 1 when not being controlled. When expecting that the principal controls, agents' transfer is crowded out by 1.3 points on average in a between-group matching, while it is only crowded out by 0.43 points in a within-group matching (30\% of crowding out in a between-group matching). Similarly, when agents believe that principals will not control, crowding out amounts to 2.6 points in a between-group matching, but 1.9 points in a within-group matching (73\% of crowding out in the between-group matching).

Table 2 shows the hostility effect in an OLS regression in which the dependent variable is the extent of crowding out. To capture the "hostility effect" we add as independent variables, first, a dummy for whether the principal-agent interaction is within-group and, second, we add agents' beliefs about principal's behavior. The specification of main interest is Column (1) on which the estimation of our simple model is based. Additionally, we include transfer when not being controlled (Column (2)) and transfer when not being controlled squared (Column (3)) as controls to demonstrate the robustness of our results. Lastly, in columns (4) to (6) we use an alternative measure of crowding out as a dependent variable, the difference between transfers when not being controlled and when being controlled divided by the transfer when not being controlled, to show that results are also robust to alternative measurements of crowding out. The results indicate that for all specifications the hostility effect (which is captured in our model by $\delta$ ) is significant, i.e., control has more "hidden costs" in between-group interactions if beliefs about principals' behavior are kept constant.

Using the three effects of group identity on the efficacy of incentives, (1) prosocial 


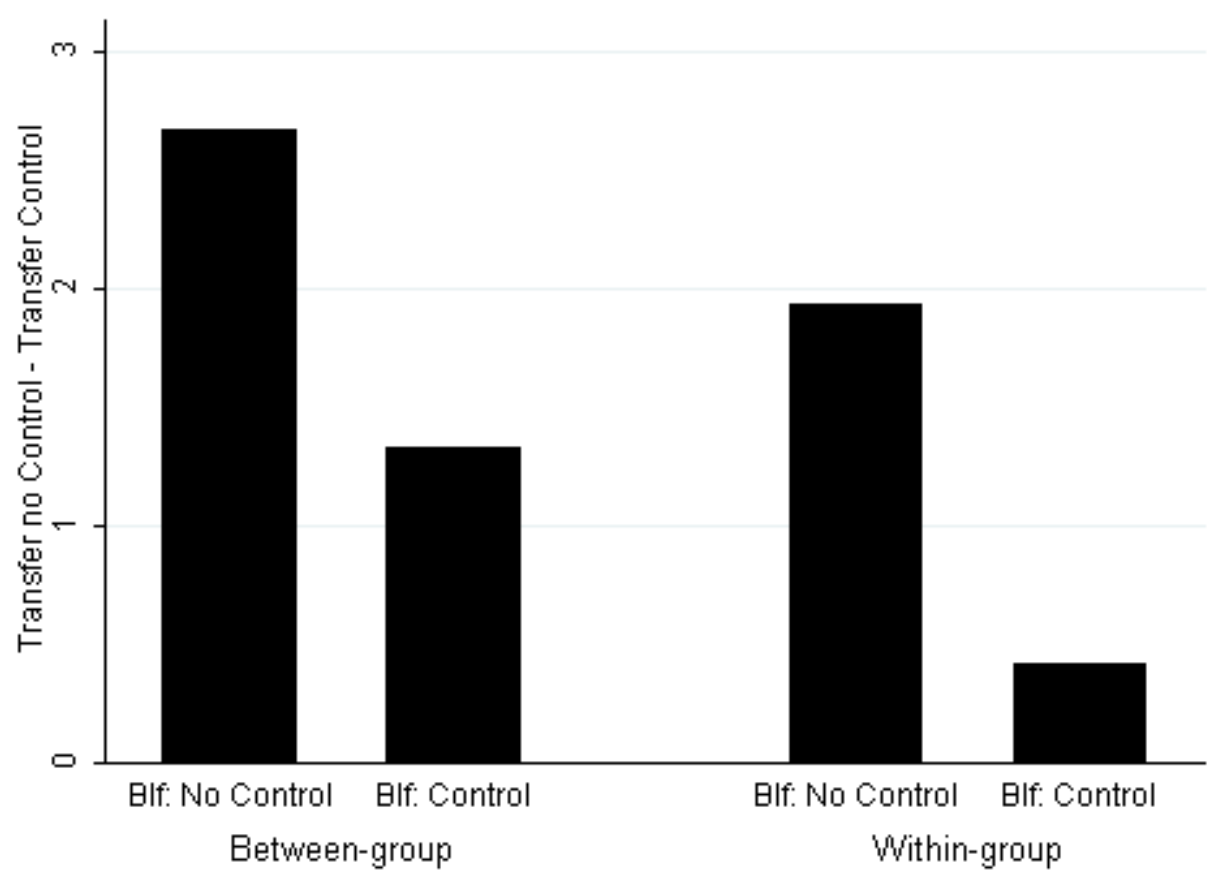

Notes: The figure depicts average crowding out, i.e., transfers under no control - transfers under control, as a function of agents's beliefs and matching. We restrict the sample to agents that transfer more than 1 when not being controlled.

Figure 4: Average Crowding Out Depending on Agents' Beliefs and Matching 
Table 2: Agents' Crowding Out

\begin{tabular}{|c|c|c|c|c|c|c|}
\hline Dependent Variable: & $\begin{array}{l}\text { Diff } \\
(1)\end{array}$ & $\begin{array}{l}\text { Diff } \\
(2)\end{array}$ & $\begin{array}{l}\text { Diff } \\
(3)\end{array}$ & $\begin{array}{c}\text { Fraction } \\
(4)\end{array}$ & $\begin{array}{c}\text { Fraction } \\
(5)\end{array}$ & $\begin{array}{c}\text { Fraction } \\
(6)\end{array}$ \\
\hline Within-group matching $(=1)$ & $\begin{array}{l}-0.806^{*} \\
(0.460)\end{array}$ & $\begin{array}{l}-1.002^{*} \\
(0.505)\end{array}$ & $\begin{array}{c}-1.008^{* *} \\
(0.489)\end{array}$ & $\begin{array}{c}-0.166^{* * *} \\
(0.0530)\end{array}$ & $\begin{array}{l}-0.145^{* *} \\
(0.0581)\end{array}$ & $\begin{array}{l}-0.145^{* *} \\
(0.0585)\end{array}$ \\
\hline Agent's Belief (Control=1) & $\begin{array}{c}-1.419^{* * *} \\
(0.500)\end{array}$ & $\begin{array}{c}-1.414^{* * *} \\
(0.485)\end{array}$ & $\begin{array}{c}-1.228^{* * *} \\
(0.445)\end{array}$ & $\begin{array}{c}-0.186^{* *} \\
(0.0723)\end{array}$ & $\begin{array}{c}-0.186^{* *} \\
(0.0718)\end{array}$ & $\begin{array}{c}-0.186^{* *} \\
(0.0717)\end{array}$ \\
\hline Transfer $($ Control=0) & no & yes & yes & no & yes & yes \\
\hline$[\text { Transfer }(\text { Control }=0)]^{2}$ & no & no & yes & no & no & yes \\
\hline$N$ & 97 & 97 & 97 & 97 & 97 & 97 \\
\hline
\end{tabular}

Notes: Standard errors are in parentheses. All columns report results of OLS regressions. We restrict the sample to agents that transfer more than 1 when not being controlled. Columns (1) - (3): dependent variable is the individual difference between transfers under no control and under control. Columns (4) (6): dependent variable is the individual difference between transfers under no control and under control divided by transfers under no control. Standard errors are clustered at the individual level.

Level of significance: ${ }^{*} \mathrm{p}<0.10,{ }^{* *} \mathrm{p}<0.05,{ }^{* * *} \mathrm{p}<0.01$

effect, (2) trust effect, (3) and hostility effect, we can now decompose the diff-in-diff and illustrate the relative importance of each of the three effects. ${ }^{18}$

Using these parameters, we get for the decomposition of the diff-in-diff:

$$
\begin{aligned}
\Pi_{w}-\Pi_{b} & =\underbrace{\left(s_{b}(0)-s_{w}(0)\right)+\left[s_{w}(>1)-s_{b}(>1)\right] \kappa}_{\text {Prosocial Effect: } 0.26} \\
& +\underbrace{\left[s_{w}(>1)\left(1-b_{w}\right)-s_{b}(>1)\left(1-b_{b}\right)\right] \gamma}_{\text {Trust Effect: } 0.59} \\
& -\underbrace{s_{b}(>1) \delta}_{\text {Hostility Effect: }-0.52} \\
& =0.33
\end{aligned}
$$

These calculations show that the effects are countervailing: while the "prosocial" and

\footnotetext{
${ }^{18}$ See section B.2 in the Appendix for the details of the calculations.
} 
the "trust" effect make control more detrimental in a within-group setting, the "hostility" that agents exhibit in a between-group matching has an influence in the opposite direction. In total, the difference between the average effect of control in a within-group matching and the average effect of control in a between-group matching is close to zero. ${ }^{19}$

\subsection{Principals' Behavior}

We now turn to principals' decision to control:

Result 8: The majority of principals does not control.

On average, $28 \%$ of principals control the agent. So, similar to Falk and Kosfeld (2006) we find that a substantial share of principals controls the agents even though the majority of principals does not control. ${ }^{20}$

Result 9: Group identity affects principals' decisions: More principals control in a between-group matching.

Principals' decision to control is influenced by group identity. The share of principals who control is $37 \%$ in a between-group and $18 \%$ in within-group interactions. The difference is statistically significant (Fisher's exact test, $\mathrm{p}<0.03$ ).

From an income maximization perspective principals do not behave optimally as not controlling is the best choice (on average). Note, however, that half of these subjects who control (wrongly) believe that agents will transfer 1 or less. Their behavior therefore is consistent with income maximization given their (incorrect) beliefs about agents' behavior. Also note that group identity affects the distribution of principals who expect

\footnotetext{
${ }^{19}$ Also note that the estimated diff-in-diff of 0.33 seem to match the actual diff-in-diff of 0.28 quite well despite the set of simplifying assumptions used in Section 3.

${ }^{20}$ In treatment C5 (table 3, p. 1621) they observe that a fraction of 0.26 of principals controls the agent.
} 
low transfers. Around $18 \%(5 \%)$ of principals expect a transfer not larger than 1 in a between-group (within-group) matching.

\section{Conclusions}

While we know that incentive systems and particular control mechanisms designed for selfish individuals may not be effective but can backfire, little is known about when the "hidden costs of control" are particularly severe. In this paper we test whether the social relationship between the principal and agent, i.e., whether they share the same group identity, affects the impact of control on the performance provided by the agents.

The results confirm that agents react negatively to control. While the overall effect of control is the same when agent and principal belong to the same group and when they belong to different groups, the mechanisms which trigger the hidden costs of control are distinct and do depend on group identity. In general, agents react more negatively when they expect principals not to control. When agent and principal share the same group identity, agents are more likely to expect not to be controlled leading to crowding out. When agent and principal belong to different groups, the hidden costs of control are due to a different mechanism. Holding agent's belief constant, agents interpret controlling from an out-group principal more 'hostile' and as a consequence reduce their transfers to the principals. In the end, control has 'hidden costs of control' in both in-group and out-group matching - but for different reasons.

The results have important implications. First, many principal-agent interactions are between individuals from different ethnic, racial or religious groups, or between different firms or, within the same firm, between workers belonging to different departments or with different responsibilities and wages. Our findings suggest that delegation schemes and 
mechanisms based on trust could be efficient also in such interactions and not necessarily only when principals and agents have close social ties.

Secondly, we isolate two different mechanisms through which control devices have detrimental effects on individual performance. We believe this may help further our understanding of the general conditions under which incentives have the potential to be detrimental and of the factors that are likely to determine the size of the "hidden costs" of incentives. Moreover, the group-specific mechanisms for how control is perceived indicate that it is important to take group structures into account when designing optimal incentive schemes. As suggested by Akerlof and Kranton (2005), group identity does affect principal-agent relationships and the way incentives work. Whether the principal and the agent share the same identity, i.e., are in-group members, changes in important ways how incentive and control mechanisms are perceived.

Future work should extend this line of research to investigate the impact of group identity on other aspects of principal-agent relations, for example hold-up problems. Additionally, while control can be understood as a special form of an incentive scheme, future research should test the effect of group identity for many different incentive systems, like bonuses or penalties.

\section{References}

Akerlof, George and Rachel Kranton, "Identity and the Economics of Organizations," Journal of Economic Perspectives, 2005, 19, 9 - 32.

Allison, Scott T. and David M. Messick, "The Group Attribution Error," Journal of Experimental Social Psychology, 1985, 21 (6), 563-579.

Bandiera, Oriana, Iwan Barankay, and Imran Rasul, "Social Connections and Incentives in the Workplace: Evidence from Personnel Data," Econometrica, 2009, 77 (4), 1047-1094.

_ , _, and _ , "Social Incentives in the Workplace," Review of Economic Studies, 04 2010, 77 (2), 417-458. 
Bernhard, Helen, Ernst Fehr, and Urs Fischbacher, "Group Affiliation and Altruistic Norm Enforcement," The American Economic Review, 2006, 96 (2), 217-221.

Bohnet, Iris and Bruno S. Frey, "Social Distance and Other-Regarding Behavior in Dictator Games: Comment," The American Economic Review, 1999, 89 (1), 335-339.

Brandts, Jordi and Gary Charness, "The Strategy versus the Direct-Response Method: A First Survey of Experimental Comparisons," Experimental Economics, January 2011,14 (3), 375-398.

Charness, Gary, Luca Rigotti, and Aldo Rustichini, "Individual Behavior and Group Membership," The American Economic Review, 2007, 97 (4), 1340-52.

_ , Ramon Cobo-Reyes, Natalia Jiménez, Juan Lacomba, and Francisco Lagos, "The Hidden Advantages of Delegation: Pareto-Improvements in a Gift-Exchange Game," The American Economic Review, May 2011, 102 (5), 2358-79.

Chen, Roy and Yan Chen, "The Potential of Social identity for Equilibrium Selection," The American Economic Review, 2011, 101 (6), 2562-2589.

Chen, Yan and Sherry Xin Li, "Group Identity and Social Preferences," The American Economic Review, 2009, 99 (1), 431-457.

Dickinson, David and Marie-Claire Villeval, "Does Monitoring Decrease Work Effort? The Complementarity Between Agency and Crowding-Out Theories," Games and Economic Behavior, 2008, 63 (1), 56-76.

Dufwenberg, Martin and Astrid Muren, "Generosity, Anonymity, Gender," Journal of Economic Behavior and Organization, 2006, 61 (1), 42-49.

Eckel, Catherine C. and Philip J. Grossman, "Managing Diversity by Creating Team Identity," Journal of Economic Behavior $\&$ Organization, 2005, 58 (3), 371-392.

Ellingsen, Tore and Magnus Johannesson, "Pride and Prejudice: The Human Side of Incentive Theory," The American Economic Review, 2008, 98 (3), 990-1008.

Falk, Armin and Christian Zehnder, "Discrimination and In-Group Favoritism in a Citywide Trust Experiment," Mimeo, 2007.

- and Michael Kosfeld, "The Hidden Cost of Control," The American Economic Review, 2006, 96 (5), 1611-30.

Fehr, Ernst, Alexander Klein, and Klaus Schmidt, "Fairness and Contract Design," Econometrica, 2007, 75 (1), 121-154.

- and Armin Falk, "Psychological Foundations of Incentives," European Economic Review, 2002, 46, 287-324. 
- and Bettina Rockenbach, "Detrimental Effects of Sanctions on Human Altruism," Nature, 2003, 422 (6928), 137-140.

- and John A. List, "The Hidden Costs and Returns of Incentives - Trust and Trustworthiness among CEOs," Journal of the European Economic Association, 2004, 2 (5), $743-71$.

Fershtman, Chaim and Uri Gneezy, "Discrimination in a Segmented Society: An Experimental Approach," Quarterly Journal of Economics, 2001, 116 (1), 351-377.

Fischbacher, Urs, "z-Tree: Zurich Toolbox for Ready-Made Economic Experiments," Experimental Economics, 2007, 10 (2), 171-178.

Frey, Bruno S., "Does Monitoring Increase Work Effort? The Rivalry with Ttrust and Loyalty," Economic Inquiry, 1993, 31 (4), 663-670.

- and Reto Jegen, "Motivation Crowding Theory: A Survey of Empirical Evidence," Journal of Economic Surveys, 2001, 5 (5), 589-611.

Gächter, Simon, Esther Kessler, and Manfred Königstein, "Do Incentives Destroy Voluntary Cooperation?," Working Paper, 2010.

Gneezy, Uri and Aldo Rustichini, "Pay Enough or Don't Pay at All," Quarterly Journal of Economics, 2000, pp. $791-810$.

_, Stephan Meier, and Pedro Rey-Biel, "When and Why Incentives (Don't) Work to Modify Behavior," Journal of Economic Perspectives, 2011, 25 (4).

Götte, Lorenz, David Huffman, and Stephan Meier, "The Impact of Group Membership on Cooperation and Norm Enforcement: Evidence using Random Assignment to Real Social Groups," The American Economic Review, 2006, 96 (2), 212 - 216.

${ }_{-},{ }_{-}$, and $\_,$"The Impact of Social Ties on Group Interactions: Evidence from Minimal Groups and Randomly Assigned Real Groups," American Economic Journal: Microeconomics, 2012, 4 (1), 101-15.

_, , , , and Matthias Sutter, "Competition Between Organizational Groups: Its Impact on Altruistic and Anti-Social Motivations," Management Science, 2012, 58 (5), 948-960.

Greiner, Ben, "The Online Recruitment System ORSEE 2.0 - A Guide for the Organization of Experiments in Economics," Working Paper Series in Economics 10, University of Cologne, Department of Economics June 2004.

Hastie, Reid, "Social Inference," Annual Review of Psychology, 1983, 34 (1), 511-542.

Hewstone, Miles, Mark Rubin, and Hazel Willis, "Intergroup Bias," Annual Review of Psychology, 2002, 53, 575-604. 
Heyman, James and Dan Ariely, "Effort for Payment: A Tale of Two Markets," Psychological Science, 2004, 15 (11), 787-93.

Kessler, Judd and Stephen Leider, "Finding the Hidden Cost of Control," Working Paper, 2012.

Kogut, Bruce and Udo Zander, "What Firms Do? Coordination, Identity, and Learning," Organization Science, 1996, 7 (5), 502-518.

Lazear, Edward P., "Performance Pay and Productivity," The American Economic Review, December 2000, 90 (5), 1346-1361.

Siemens, Ferdinand Von, "Intention-Based Reciprocity and the Hidden Costs of Control," Working Paper, 2011.

Sliwka, Dirk, "Trust as a Signal of a Social Norm and the Hidden Costs of Incentive Schemes," The American Economic Review, 2007, 97 (3), 999-1012.

Sutter, Matthias, "Individual Behavior and Group Membership: Comment," The American Economic Review, 2009, 99 (5), 2247-57.

Tajfel, Henri, "Social Psychology of Intergroup Relations," Annual Review of Psychology, 1982, 33 (1), 1-39.

- and J. C. Turner, "An Integrative Theory of Intergroup Conflict," in W. G. Austin and S. Worchel, eds., The Social Psychology of Intergroup Relations, Brooks/Cole, 1979, pp. $34-47$.

Tremewan, James, "Group Identity and Coalition Formation: Experiments in One-shot and Repeated Games," Working Paper, 2010.

Ziegelmeyer, Anthony, Katrin Schmelz, and Matteo Ploner, "Hidden Costs of Control: Four Repetitions and an Extension," Experimental Economics, June 2012, 15 (2), 323-340. 


\section{Appendix}

\section{A Descriptive Statistics}

Table A1: Agents' Behavior by Matching

\begin{tabular}{|c|c|c|c|c|c|c|}
\hline \multicolumn{7}{|c|}{ In-Group Matching } \\
\hline & mean & $\mathrm{sd}$ & median & $\min$ & $\max$ & $\mathrm{N}$ \\
\hline Transfer if Control $=0$ & 6.140625 & 5.811503 & 6 & 0 & 24 & 64 \\
\hline Transfer if Control $=1$ & 4.90625 & 5.764475 & 4 & 1 & 24 & 64 \\
\hline Agent's Belief (Control=1) & .265625 & 4451569 & 0 & 0 & 1 & 64 \\
\hline \multicolumn{7}{|c|}{ Out-Group Matching } \\
\hline & mean & sd & median & $\min$ & $\max$ & \\
\hline Transfer if Control $=0$ & 3.46875 & 3.771105 & 2 & 0 & 18 & 64 \\
\hline Transfer if Control $=1$ & 2.515625 & 2.63669 & 1 & 1 & 15 & 64 \\
\hline Agent's Belief (Control=1) & .671875 & 4732424 & 1 & 0 & 1 & 64 \\
\hline
\end{tabular}

Table A2: Principals' Behavior by Matching

\begin{tabular}{|c|c|c|c|c|c|c|}
\hline \multicolumn{7}{|c|}{ In-Group Matching } \\
\hline & mean & $\mathrm{sd}$ & median & $\min$ & $\max$ & $\mathrm{N}$ \\
\hline \multirow[t]{3}{*}{ Decision $($ Control $=1$ ) } & .1875 & .3933979 & 0 & 0 & 1 & 64 \\
\hline & \multicolumn{6}{|c|}{ Out-Group Matching } \\
\hline & mean & $\mathrm{sd}$ & median & $\min$ & $\max$ & $\mathrm{N}$ \\
\hline Decision (Control=1) & .375 & 48795 & 0 & 0 & 1 & 64 \\
\hline
\end{tabular}




\section{B For Online Publication}

\section{B.1 Derivation of Equation 1}

The crowding out effect for matching $m$ is:

$$
\Pi_{m}=-s_{m}(0)+s_{m}(>1)\left[b_{m} \pi(m, c)+\left(1-b_{m}\right) \pi(m, n)\right]
$$

Using $\pi(w, c)=\kappa$ and $\pi(w, n)=\kappa+\gamma$, we get in a within group matching:

$$
\begin{aligned}
\Pi_{w} & =-s_{w}(0)+s_{w}(>1)\left[b_{w} \pi(w, c)+\left(1-b_{w}\right) \pi(w, n)\right] \\
& =-s_{w}(0)+s_{w}(>1)\left[b_{w} \kappa+\left(1-b_{w}\right)(\kappa+\gamma)\right] \\
& =-s_{w}(0)+s_{w}(>1)\left[\kappa+\left(1-b_{w}\right) \gamma\right]
\end{aligned}
$$

Using $\pi(b, c)=\kappa+\delta$ and $\pi(b, n)=\kappa+\gamma+\delta$, we can derive the crowding out effect in a between group matching:

$$
\begin{aligned}
\Pi_{b} & =-s_{b}(0)+s_{b}(>1)\left[b_{b} \pi(b, c)+\left(1-b_{b}\right) \pi(b, n)\right] \\
& =-s_{b}(0)+s_{b}(>1)\left[b_{b}(\kappa+\delta)+\left(1-b_{b}\right)(\kappa+\delta+\gamma)\right] \\
& =-s_{b}(0)+s_{b}(>1)\left[\kappa+\delta+\left(1-b_{b}\right) \gamma\right]
\end{aligned}
$$

Lastly, substracting 5 from 4 yields

$$
\begin{aligned}
\Pi_{w}-\Pi_{b} & =\underbrace{\left(s_{b}(0)-s_{w}(0)\right)+\left[s_{w}(>1)-s_{b}(>1)\right] \kappa}_{\text {Prosocial Effect }} \\
& +\underbrace{\left[s_{w}(>1)\left(1-b_{w}\right)-s_{b}(>1)\left(1-b_{b}\right)\right] \gamma}_{\text {Trust Effect }} \\
& -\underbrace{s_{b}(>1) \delta}_{\text {Hostility Effect }}
\end{aligned}
$$

\section{B.2 Calibration of the Model}

We now turn to the decomposition of the diff-in-diff as described in section 3. In Table B1, we regressed the individual crowding out on agent's beliefs and matching for agents who transfer more than 1 under no control. This allows us to identify $\kappa, \gamma$, and $\delta$. The regression (see Table B1) delivers the following parameter values: 
- $\pi(w, c)=\kappa=2.71-1.41-0.8=0.5$

- $\pi(w, n)=\kappa+\gamma=2.71-0.8=1.91$

- $\pi(b, c)=\kappa+\delta=2.71-1.41=1.3$

- $\pi(b, n)=\kappa+\delta+\gamma=2.71$

Hence, $\gamma=1.41$ and $\delta=0.8$. From above we already have $s_{b}(0)=0.28, s_{b}(>1)=$ $0.66, s_{w}(0)=0.12, s_{w}(>1)=0.86, b_{b}=0.57 b_{w}=0.18$. Using these parameters, we get for the decomposition of the diff-in-diff:

$$
\begin{aligned}
& \left.\Pi_{w}-\Pi_{b}=\underset{s_{w}}{\left.(>1)\left(1-b_{w}\right)-s_{b}(>1)\left(1-b_{b}\right)\right] \gamma-s_{b}(>1) \delta}+s_{w}(0)\right) \\
& =0.16+(0.86-0.66) * 0.5+(0.86 * 0.82-0.66 * 0.43) * 1.4-0.66 * 0.8 \\
& =0.26 \text { (Prosocial Effect) }+0.59 \text { (Trust Effect) }-0.52 \text { (Hostility Effect) } \\
& =0.33
\end{aligned}
$$

Table B1: Crowding out of Agents' Transfers

\begin{tabular}{lc}
\hline \hline Dependent Variable: Transfer & $(1)$ \\
\hline Within-group matching $(=1)$ & $-0.806^{*}$
\end{tabular}

Agent's Belief (Control=1) $\quad-1.419^{* * *}$

Constant

$$
2.716^{* * *}
$$

\begin{tabular}{l}
\hline$N$ \\
\hline$\overline{N o t e s: ~ S t a n d a r d ~ e r r o r s ~ a r e ~ i n ~ p a r e n t h e s e s . ~ T a b l e ~ r e-~}$ \\
port results of OLS regression. Dependent variable \\
is the individual difference between transfers under \\
control and under no control. We restrict the sample \\
to agents that transfer more than 1 when not being \\
controlled. Standard errors are clustered at the in- \\
dividual level. \\
Level of significance: $* \mathrm{p}<0.10, * * \mathrm{p}<0.05, * * *$ \\
$\mathrm{p}<0.01$
\end{tabular}




\section{B.3 Robustness Dictator Game}




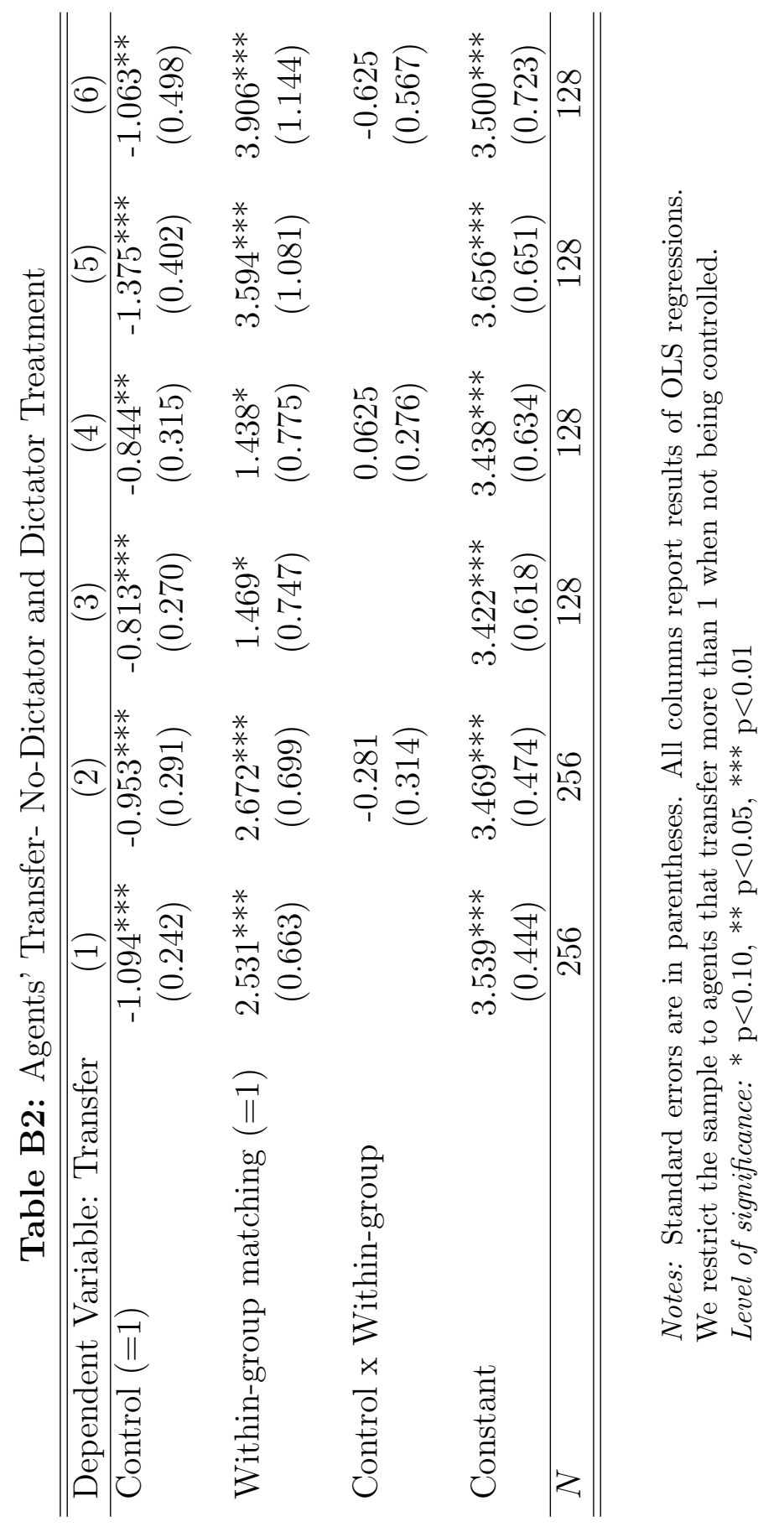


Table B3: Agents' Crowding Out - No-Dictator and Dictator Treatment

\begin{tabular}{lccc}
\hline \hline Dependent Variable: Diff & $(1)$ & $(2)$ & $(3)$ \\
\hline Within-group matching (=1) & $-0.806^{*}$ & -0.893 & $-0.807^{*}$ \\
& $(0.460)$ & $(0.842)$ & $(0.409)$ \\
& & & \\
Agent's Belief (Control=1) & $-1.419^{* * *}$ & $-2.040^{* *}$ & $-0.907^{*}$ \\
& $(0.500)$ & $(0.840)$ & $(0.478)$ \\
Constant & $2.716^{* * *}$ & $3.474^{* * *}$ & $2.086^{* * *}$ \\
& $(0.558)$ & $(1.007)$ & $(0.455)$ \\
\hline$N$ & 97 & 48 & 49 \\
\hline \hline
\end{tabular}

Notes: Standard errors are in parentheses. All columns report results of OLS regressions.

Level of significance: ${ }^{*} \mathrm{p}<0.10,{ }^{* *} \mathrm{p}<0.05,{ }^{* * *} \mathrm{p}<0.01$

\section{B.4 Robustness Full Sample}

In this section, we reproduce our estimation of Table 2 including the full sample. That is, also subjects who exhibit a transfer of zero or one when not being controlled are now included in the estimation. Clearly, from our discussion of the behavioral model in section 3 this inclusion is not adequate in the light of our proposed explanation of crowding out. By definition, we can only observe crowding out when subjects transfer more than $1 .^{21}$ Moreover, trust as well as hostility can only play a role for subjects for whom we observe crowding out. Nevertheless, we present these results here to show the robustness of our estimations and graphs presented in the main text.

Comparing Table B4 to Table 2, it becomes evident that results are very similar. The only difference appears in specification (1): When the full sample is included, the coefficient of the matching dummy (Within-group matching $(=1)$ ) changes to -0.4 and is not significant anymore. Once we control for the transfer, the size as well as significance of this coefficient is restored. The difference is to be expected as in a between-group matching a disproportional share of subjects transfers zero or one thereby exhibiting no or even negative crowding out. This obviously upwards biases the estimator of the matching dummy.

\footnotetext{
${ }^{21}$ For subjects who transfer zero when not being controlled crowding out can actually be negative as those subjects are pushed to a transfer of at least one. That is also why, when we control for agents who believe to be controlled in a within-group matching, we observe aggregate crowding out of zero (Figure $\mathrm{B} 2)$.
} 


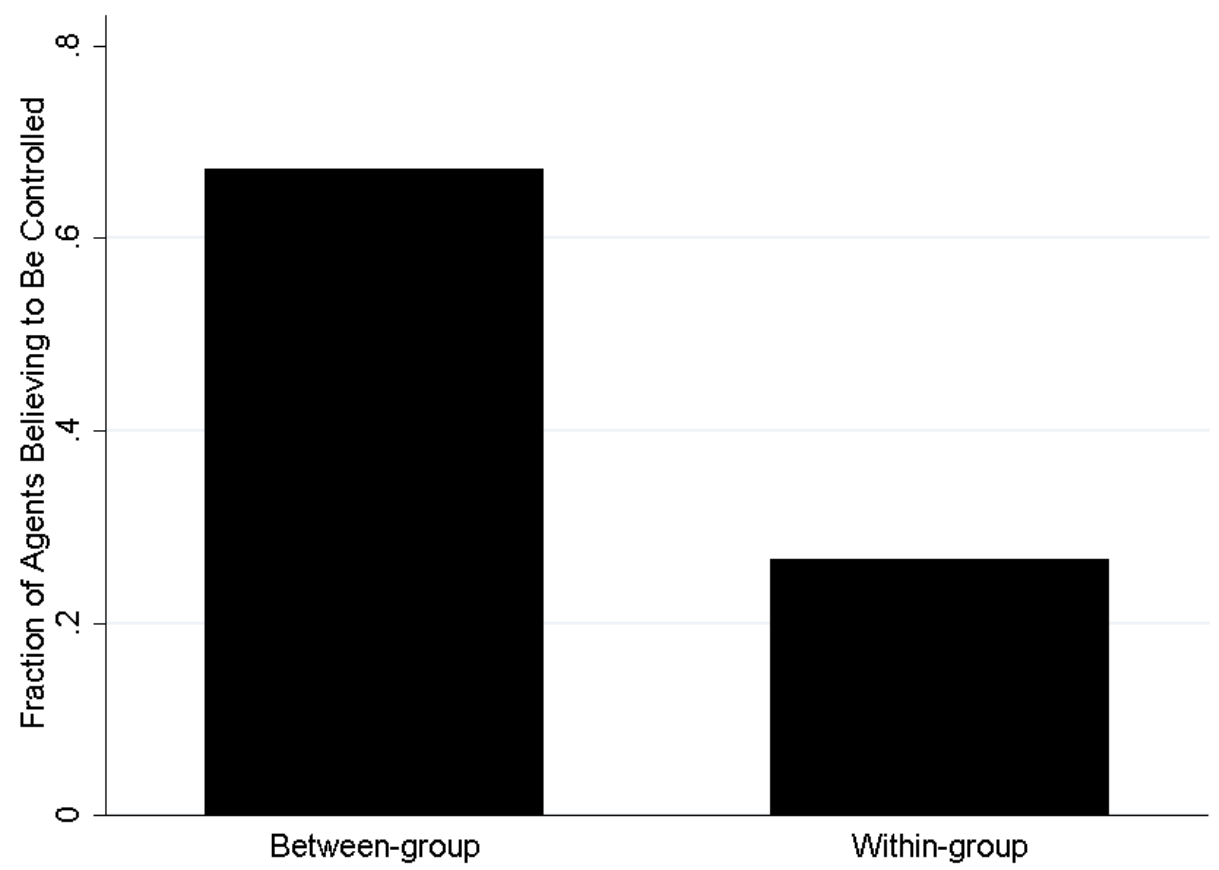

Notes: The figure depicts average individual beliefs about being controlled as a function of matching.

Figure B1: Average Beliefs about Principal's Decision to Control 


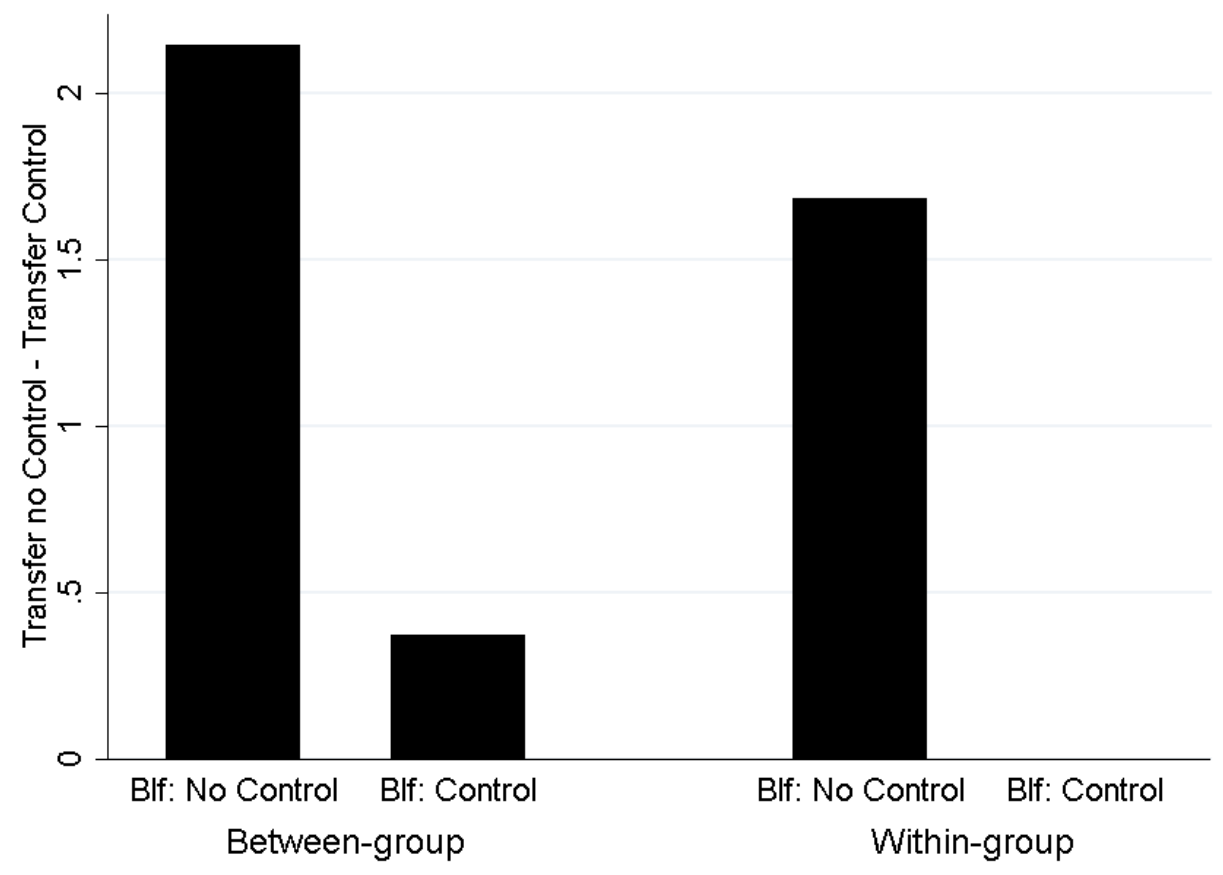

Notes: The figure depicts average crowding out, i.e., transfers under no control - transfers under control, as a function of agents's beliefs and matching.

Figure B2: Average Crowding Out Depending on Agents' Beliefs and Matching 
Table B4: Agents' Crowding-Out - all subjects

\begin{tabular}{lcccccc}
\hline \hline Dependent Variable: & $\begin{array}{c}\text { Diff } \\
(1)\end{array}$ & $\begin{array}{c}\text { Diff } \\
(2)\end{array}$ & $\begin{array}{c}\text { Diff } \\
(3)\end{array}$ & $\begin{array}{c}\text { Fraction } \\
(4)\end{array}$ & $\begin{array}{c}\text { Fraction } \\
(5)\end{array}$ & $\begin{array}{c}\text { Fraction } \\
(6)\end{array}$ \\
\hline Within-group matching $(=1)$ & -0.421 & $-0.773^{*}$ & $-0.801^{* *}$ & $-0.153^{* * *}$ & $-0.145^{* *}$ & $-0.148^{* *}$ \\
& $(0.396)$ & $(0.395)$ & $(0.393)$ & $(0.0530)$ & $(0.0596)$ & $(0.0594)$ \\
Agent's Belief (Control=1) & $-1.729^{* * *}$ & $-1.467^{* * *}$ & $-0.965^{* * *}$ & $-0.214^{* *}$ & $-0.215^{* * *}$ & $-0.195^{* *}$ \\
& $(0.454)$ & $(0.397)$ & $(0.352)$ & $(0.0804)$ & $(0.0804)$ & $(0.0796)$ \\
& & $0.172^{* *}$ & $0.633^{* * *}$ & & -0.00374 & 0.0355 \\
Transfer (Control=0) & & $(0.0697)$ & $(0.102)$ & & $(0.00652)$ & $(0.0319)$ \\
& & & $-0.0223^{* * *}$ & & & -0.00168 \\
& & & $(0.00398)$ & & & $(0.00116)$ \\
\hline Transfer (Control=0) $]^{2}$ & 128 & 128 & 128 & 102 & 102 & 102 \\
\hline$N$
\end{tabular}

Notes: Standard errors are in parentheses. All columns report results of OLS regressions. Dependent variable is the individual difference between transfers under control and under no control.

Level of significance: ${ }^{*} \mathrm{p}<0.10,{ }^{* *} \mathrm{p}<0.05,{ }^{* * *} \mathrm{p}<0.01$ 


\section{B.5 Instructions}


This is the English translation of the instructions (original in German). Instructions of part I were displayed directly on screen; instructions of part II were handed out. Beginning at the $11^{\text {th }}$ screen, the participant had a banner displaying the group she belonged to at the top of every screen, which is not displayed here. The instructions of part I are based on the instructions of Chen and Li (2009). The instructions of part II are based on the instructions of Falk and Kosfeld (2006).

\section{Part I}

$\left[1^{\text {st }}\right.$ screen]

You are now participating in an economic experiment. The income you can earn in the course of this experiment depends on your decisions and the other participants' decisions. The experiment consists of two parts and <no of participants> persons take part.

During the experiment, your income will be denoted in points. Your final income consists of the income you earn in the two parts of the experiment. At the end of the experiment, you will be paid out in cash. Please note that:

$$
2 \text { points }=1 € .
$$

All decisions will be made anonymously. At the end of the experiment, each participant will be paid out in private.

If you have any questions, please ask for assistance. Your question will be answered at your workplace. Please do not talk to any of the other participants during the experiment.

[2 $2^{\text {nd }}$ screen $]$

In Part 1 everyone will be shown 5 pairs of paintings by two artists. The paintings were created by two distinct painters. Each pair of paintings consists of one painting being made by each artist. For each pair, please choose the painting you prefer. According to the paintings you and the other participants choose, you (and the other participants) will be classified into two equally large groups.

The participants you are grouped with will be the same for the rest of the experiment.

After Part 1 has finished, you will be given further instructions.

[3 ${ }^{\text {rd }}$ screen]

Now, please choose which painting you prefer by clicking on one of the buttons.

After everyone has submitted answers, you will be privately informed of which group you are in.

[4 $4^{\text {th }}$ to $9^{\text {th }}$ screen]

Pair \#: Please select which painting you prefer

$$
\text { <Picture 1> <Picture 2> }
$$

[10 ${ }^{\text {th }}$ screen]

I prefer this painting I prefer this painting 
You are assigned to the < "Kandinsky" - "Klee" > group.

The number of people in your own group is <Number of Group Members> .

$\left[11^{\text {th }}\right.$ screen $]$

You will now receive two more paintings (painting \#6 and \#7) and 3 skill questions. Please select the artist who you think created the paintings and answer the skill questions as best as you can, respectively. The correct answers of a group will be summed up and divided by the number of group members. The group which achieves the highest average will receive a prize of 16 points per group member. That is, each member of this group will receive an additional payment of 16 points at the end of the experiment. The other group obtains no payment.

In the case of a tie, the computer will randomly determine one group which receives the prize.

You will be informed of which group received the prize at the end of the experiment.

Meanwhile, you can use a group chat program to get help from or offer help to other members in your own group. Except for the following restrictions, you can type whatever you want in the lower box of the chat program. Messages will be shared among all the members from your own group. You will not be able to see the messages exchanged among the other group. People in the other group will not see the messages from your own group either.

Restrictions on messages

1. Please do not identify yourself or send any information that could be used to identify you (e.g. age, subject, sex, etc.).

2. Please refrain from using obscene or offensive language.

$\left[12^{\text {th }}\right.$ screen]

$<$ Picture 6> This painting is by $<$ "Klee" $>$ is by $<" K a n d i n s k y ">$

$<$ Picture $7>$ This painting is by $<$ "Klee" $>$ is by $\langle$ "Kandinsky" $>$

Type your comments below then press Enter

$<$ Chat Box $>$

$\left[13^{\text {th }}\right.$ screen]

Question 1: What was the inflation rate in Germany in 2010 (in \%)?

Question 2: What was the budget of the German Department of Defense in 2007 (in Million EUR)?

Question 3: How many members does the current federal cabinet of Germany (as of June 2011) have?

Answer 1: The inflation in Germany in 2010 was a) $1.1 \%$ b) $1.8 \%$ c) $2.1 \%$

Answer 2: The federal budget was a) 24519 b) 27578 c) 31560

Answer 3: The current cabinet comprises (June 2011) the following number of members

a) 13 b) $16 \mathrm{c}) 17$ 
Type your comments below then press Enter

$<$ Chat Box>

$\left[14^{\text {th }}\right.$ screen]

You have finished part I of the experiment. As soon as all participants have completed part I, the experiment continues. 


\section{Part II}

This part of the experiment comprises two rounds. You can earn points in both rounds. As before it holds that:

\section{2 points = 1 Euro}

Your final income in part II will be determined by one of these rounds. The round determining your income will be randomly drawn by the computer at the end of the experiment. It is the same round for each participant.

At the beginning of part II, the computer will randomly draw each participant either as participant A or as participant B. This assignment will be kept the same during part II. That is, a participant is either participant $A$ or participant $B$ during the two rounds.

In both rounds, two participants A and B are randomly associated.

In the second round, each participant A will be associated with another participant B than in the first round.

Hence, the association is such that the same participants A and B will never be associated twice.

No participant knows with whom he is associated meaning that all decisions are made anonymously. Yet, each participant knows the group membership of the participant he is associated with.

At the beginning of each round, participant A receives an amount of 24 points. Participant B receives no points.

\section{Participant A's decision:}

Participant A can decide how many points he wants to transfer to participant B. The experimenter triples each point which A transfers to B. Thus, each point which A transfers to B reduces A's income by one point and increases B's income by three points.

The formula for calculating income is as follows:

Participant A's income: 24 - transfer

Participant B's income: $0+3 *$ transfer 
The following examples will clarify the income formulas:

Example 1: A transfers 0 points to B. The incomes are then 24 for $\mathrm{A}$ and 0 for $\mathrm{B}$. Example 2: A transfers 4 points to B. The incomes are then 20 for $\mathrm{A}$ and 12 for $\mathrm{B}$. Example 3: A transfers 16 points to B. The incomes are then 8 for A and 48 for B.

\section{Participant B's decision:}

Before A decides how many points he wishes to transfer to $\mathrm{B}, \mathrm{B}$ can determine a minimum transfer. In particular, B can constrain his associated participant A to transfer him at least 1 point. However, he can also decide not to limit participant $\mathrm{A}$ and thus leave his transfer decision completely free.

Therefore, there are two cases:

Case 1: Participant $B$ constrains participant $A$ to transfer at least 1 point to him. In this case, participant A can transfer any (integer) amount between 1 and 24 to $B$.

Case 2: Participant B allows participant A to decide on his transfer freely and does not constrain him to transfer at least 1 point to him. In this case, participant A can transfer any (integer) amount between 0 and 24 to B.

Therefore, the experiment consists of two stages:

\section{Stage 1:}

In stage $1, \mathrm{~B}$ decides if he will constrain $\mathrm{A}$ to transfer at least 1 point to him, or if he will allow A to decide freely.

\section{Stage 2:}

In stage $2, \mathrm{~A}$ decides which amount he will transfer to $\mathrm{B}$. This amount lies

- between 1 and 24, if B constrains A to transfer at least 1 point;

or

- between 0 and 24, if B does not constrain A to transfer at least 1 point.

The round is completed as soon as A has decided how many points he will transfer to B.

A and B will make their entries with the help of a computer monitor. 
Please note: Participant A must decide which amount he will transfer to B before he knows whether or not $B$ will constrain him to transfer at least 1 point. This means that $A$ has to make two decisions. A can make his entries with the help of this monitor:

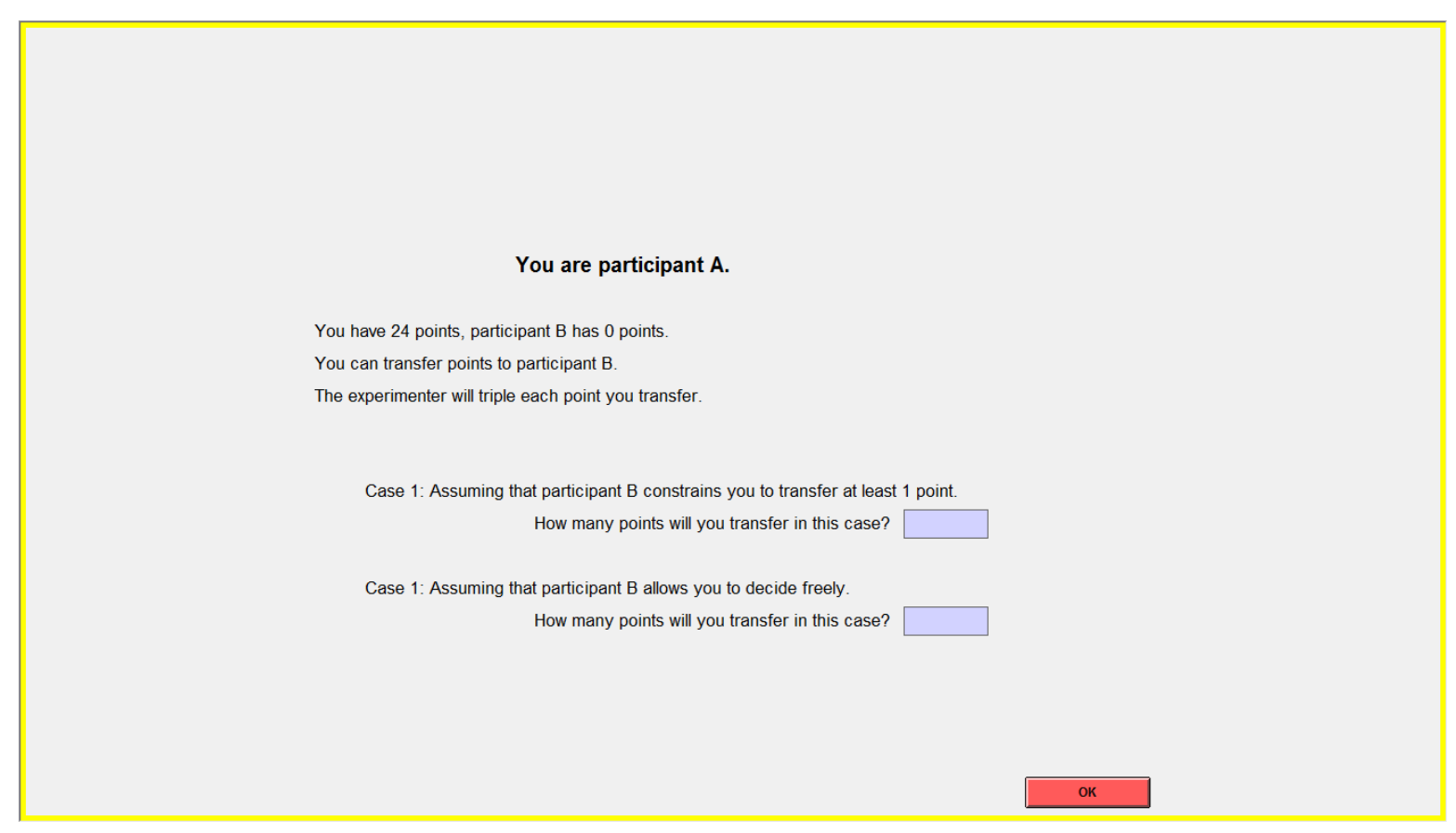

Therefore, A indicates how many points he transfers to B when B constrains him to transfer at least 1 point (case 1) and how many points he will transfer when he is free to decide (case 2).

Which of the decisions is relevant for A depends on what B decides. If he constrains $\mathrm{A}$ to transfer at least 1 point, the decision A gives under case 1 applies. If he leaves A free in his decision, the point amount which $\mathrm{A}$ indicates under case 2 applies.

A final income monitor will inform you of the randomly drawn round and the resulting incomes.

At the end of the experiment, your point income of the randomly drawn round will be converted to EUR. This amount will be paid out to you in cash. If you belong to the group which won the prize in the first part of the experiment, you will be paid out this prize in addition.

Do you have any questions?

Please solve the following control questions. They have no consequence on your income and only serve to check if all participants in the experiment have understood the rules. 
Question 1: Assume that participant B allows A to decide freely. A transfers 4 points. What are the incomes?

Income for $\mathrm{A}$ :

Income for B:

Question 2: Assume that participant B constrains A to transfer at least 1 point. A transfers 1 point. What are the incomes?

Income for A:

Income for B:

Question 3: Assume that participant B allows A to decide freely. A transfers 0 points. What are the incomes?

Income for A:

Income for B:

Please raise your hand when you have solved the control questions. 